\title{
4 \\ El Capital en las Cooperativas
}

Ernesto G.F. Luna

El presente trabajo es una «aproximación(*) al tratamiento del Capital en las Cooperativas».

\section{INTRODUCCION}

Al comenzar el Siglo XXI y en la alborada del tercer milenio de la Era Cristiana, se mantienen vigentes los principios que inspiran la «Cooperación libre», e impulsan al Movimiento Cooperativista Universal. En expresión del Profesor Jorge Sebastián MURARO, «con razón —en estricta Doctrina - el Cooperativismo como partícipe natural realizador del principio ético de solidaridad social, sigue siendo el exponente mejor calificado dentro de las denominadas "organizaciones intermedias" o entidades cogestoras del bien común socializador. Sus múltiples actividades constituyen, conforman y sostienen ese vital movimiento de asociación democrática, libre e igualitaria que introduce el "sistema social del trabajo humano" (...). Con esa aspiración y ese espíritu solidario, ejemplo irrefutable en la práctica auténtica de los valores éticos del solidarismo en la actividad socioeconómica, es el modelo incuestionable de la acción cooperativa que inspira, genera y desarrolla el activísimo Movimiento Social del Cooperativismo de

* «Appropinquare», verbo latino que significa, acercarse, aproximarse; en inglés, approach; y en francés, aperçu: esbozo, bosquejo, resumen, repaso, tanteo, ojeada, golpe de vista. 
notable e indiscutible raigambre democrática, esencialmente distinto de los "socialismos" extremos o mitigados, pero también distante de los "capitalismos" pretéritos o actuales y profundamente apartado aún más de ciertos "corporativismos" donde la unión se impone por medio de la coacción, la intimidación o la fuerza de intereses compulsivos...» (1).

La compleja, acelerada y cambiante realidad, presenta desafíos y oportunidades de innovación a la economía solidaria, al sistema productivo, financiero, monetario y comercial. De allí que las empresas cooperativas, en su multiforme actividad, integradas horizontal y verticalmente, han de empeñarse en lograr la transformación organizacional, aplicando criterios de calidad total y excelencia para optimizar el gerenciamiento de los recursos escasos, según las exigencias de un mundo marcadamente competitivo y de una economía de mercado de libre concurrencia. Ello supone también, propiciar normas jurídicas en la materia, acordes a un acelerado proceso de "transnacionalización e interdependencia», pues en expresión del muy apreciado y distinguido Académico Dr. Pedro José FRIAS, «la globalización exige ser más provincianos y cosmopolitas...» (2).

Es para mí un motivo de profunda satisfacción e íntima alegría, redactar, con gratitud y afecto, esta nota para el "Boletín de la Asociación Internacional de Derecho Cooperativo», que tiene su sede en la Facultad de Derecho de la Universidad de Deusto, en Bilbao, España, desde donde irradia el importante, interesante, sugestivo y necesario conocimiento científico en la materia, con estimulante espíritu de cooperación. El tema del capital es de interés teórico-práctico y reviste importancia para el normal desenvolvimiento institucional de las cooperativas.

A los fines de cumplir satisfactoriamente con los objetivos Estatutarios, las cooperativas, como las demás empresas, necesitan disponer de suficiente capital, patrimonio, caudal, dinero, fortuna o bienes; de lo contrario sus enunciados quedarían reducidos a buenas intenciones dejando una secuela de frustraciones. La existencia plantea la alternativa de evolucionar con criterio doctrinario sustentable, o perecer. De allí que la problemática del capital deba abordarse con espiritu y método científico, acorde a las disciplinas jurídicas, económico-sociales, políticas y éticas, es decir, objetivamente, desprejuiciadamente, metódicamente, con visión epistemológica. Así otros investigadores podrán confirmar o refutar el hecho acota- 
do que en su fase inicial se intenta describir, sin desconocer que es menester estimular a los equipos interdisciplinarios, a los efectos de que aporten una "Teoría del desarrollo (3) integral, sustentable, sostenible», consecuente con el humanismo, en una sociedad civil de libertades, solidaria para el trabajo científico-tecnológico, la generación de riquezas, con justicia social y una cultura de la calidad de vida.

\section{EL COOPERATIVISMO EN LAS CONSTITUCIONES COMPARADAS}

La Constitución de la Provincia de Santa Fe, R. A., (1962), en su Preámbulo, formula el propósito de: «fomentar la cooperación y solidaridad sociales...», e «impulsar el desarrollo económico bajo el signo de la justicia social...». Y en los Arts. 26 y 28 insiste en el «fomento del cooperativismo...». Dichos Postulados y Principios Socioeconómicos son afines, conexos y concordantes con los enunciados de las Constituciones Comparadas:

\section{II.1. Nacionales}

\section{II.1.1. De la Nación Argentina (1994)}

"Art. 14: Derecho de asociación con fines útiles». Art. 75 incs. 19 y 22: «Promoción del desarrollo humano y el progreso económico con justicia socia/». Art. 124: "Las Provincias pueden crear regiones para el desarrollo económico-social».

\section{II.1.2. De la Provincia de Buenos Aires (1994)}

Arts. 11 y 41: Promueve «el desarrollo integral y la participación económica y social mediante el cooperativismo y el mutualismo».

\section{II.1.3. De la Ciudad Autónoma de Buenos Aires (1996)}

«Art. 45: Consejo Económico y Social». «Art. 48: Política de Estado para que la actividad económica sirva al desarrollo de la persona y la justicia social». Art. 80 inc. 2 c: "Atribuciones de la Legislatura: Promoción del desarrollo económico y tecnológico y de Política Industrial» (4). 


\section{II.2. Extranjeras}

II.2.1. De la República Federal de Alemania (1949-Unificación 23-05-1990)

«Art. 9 inc. 1 y 3: Derecho de asociación». «Art. 20 inc. 1: Estado Federal, Democrático y Social». "Art. 23: R.F.A. y la Unión Europea aseguran Principios democráticos de Derecho Social, Federal y el Principio de Subsidiariedad», «Art. 74 inc. 3: Derecho de asociación».

\section{II.2.2. De la República Francesa (1995)}

«Ratifica su adhesión a los Derechos Humanos, tal y como fueron definidos por la Declaración de 1789, confirmada y completada en el Preámbulo Constitucional de 1946 y los Principios Políticos, Económicos y Sociales de 1995». "Art. 17: República indivisible, laica, democrática y social». "Arts.: 69, 70 y 71: El Consejo Económico y Social».

\section{II.2.3. De la República Italiana (1947)}

«Art. 1: Principios Fundamentales. República democrática fundada en el trabajo». "Art. 2: Reconocer los Derechos del Hombre, exige los deberes de solidaridad política, económica y social». "Art. 18: Derecho de asociación». "Art. 45: Función Social de las Cooperativas».

\section{II.2.4. Del Reino de España (1978)}

«La Nación Española deseando el bienestar (...) proclama su voluntad de garantizar la convivencia democrática dentro de la Constitución y las leyes conforme a un orden económico y social justo». "Art. 22 inc. 1: Derecho de asociación». "Art. 129: Los Poderes Públicos promoverán las sociedades cooperativas» (5).

\section{DEL CAPITAL Y LAS CUOTAS SOCIALES}

Las empresas cooperativas se desenvuelven en un sistema económico mixto, dinamizado por los sectores privado y público. Ante el «fallo del mercado», no solo el Estado aporta soluciones subsidiarias. Interpreto que también las cooperativas procuran el «beneficio de sus 
afiliados», personas físicas y jurídicas, nucleadas en resguardo de sus intereses socioeconómicos y culturales, en franca competencia con las sociedades mercantiles, tributando al bien común.

La concentración económica y la «globalización» financiera e intercomunicacional, desafían la creatividad, en el management de la tecnoestructura productiva de los países. En el ámbito microeconómi$\mathrm{co}$, plantea la necesidad de innovamiento de las organizaciones, acrecentar la integración, y encarar procesos de saneamiento económicofinanciero.

Para corroborar o refutar los hechos que refieren a la magnitud del sector cooperativo y su incidencia en el «Desarrollo Humano», quienes lo deseen, pueden acudir a la búsqueda de evidencias empíricas y a los datos cuantitativos, procurando encontrar las causas y el sentido de esta realidad, de la que da cuenta la estadística matemática, sin omitir la orientación normativa, axiológica y jurídica.

En la República Argentina las cooperativas primarias y secundarias, se rigen por la Ley $N .^{\circ} 20337 / 73$. El tema referido al "Capital y las cuotas sociales», es tratado en el Capítulo IV:

Art. 24: División en cuotas Sociales. Acciones. Transferencia. Art. 25: Integración de las cuotas sociales. Art. 26: Acciones. Formalidades. Art. 27: Capital proporcional. Art. 28: Bienes aportables. Aportes no dinerarios. Art. 29: Mora en la integración. Sanciones. Art. 30: Condominio. Representante. Art. 31: Reembolso de las cuotas sociales. Art. 32: Cuotas sociales pendientes de reembolso. Art. 33: Liquidación de cuentas. Art. 34: Prenda. Embargo. Art. 35: Reducción de capital. Art. 36:Irrepartibilidad de las reservas (6).

\section{PROYECTO DE LEY DE COOPERATIVAS AGRARIAS}

En nuestros días se intercambian opiniones sobre la conveniencia y necesidad de impulsar una novísima legislación que permita adicionar, sumar, aumentar el capital accionario, para hacer frente a los múltiples y acuciantes compromisos económicos y financieros de las Cooperativas Agrarias.

Con la firma de los Señores Diputados de la Nación Argentina: Humberto Volando, Vicepresidente $2 .^{\circ}$ de la Comisión de Agricultura y Ganadería, Pedro Salvatori, René Balestra, José Gabriel Dumon y Car- 
men Dragicevic, se propicia un Proyecto de Ley de Cooperativas Agropecuarias. Entre otros fundamentos, mencionan los siguientes:

«En Argentina existen 850 cooperativas agropecuarias integradas en 12 federaciones que comercializan aproximadamente el $20 \%$ de los granos, $26 \%$ de los lácteos, $13 \%$ del vino, más del $40 \%$ del té y el tabaco, $7 \%$ de las cabezas de ganado, etc.».

Tras una serie de consideraciones sobre el actual comportamiento nacional e internacional, los autores del Proyecto manifiestan que:

«(...) Las cooperativas agropecuarias se continuarán rigiendo en lo fundamental por las disposiciones vigentes de la Ley 20337, con excepción de aquellas normas expresamente modificadas por la presente en razón de las características particulares de estas entidades y del medio y circunstancias en que deben desarrollar sus actividades».

«El Proyecto propuesto define la cooperativa agropecuaria conforme los lineamientos de la propia experiencia nacional, como así también la internacional. Es la integrada por productores agropecuarios para industrializar, comercializar y exportar su producción, proveer insumos y servicios y contribuir a su desarrollo social y cultural».

«Esta Ley también será de aplicación para las que se denominan genéricamente como cooperativas de grados superior».

«El capital de la cooperativa estará constituido por el que se integre, de conformidad por el capítulo IV de la Ley 20337. Pero además y esta es una modificación fundamental, podrá emitir capital optativo adicional en moneda nacional o extranjera».

«El carácter facultativo de este capital indica claramente que éste podrá existir o no, dependiendo de lo que disponga el estatuto social y que así lo resuelva la asamblea. Esta facultad, anteriormente permitirá a la cooperativa evaluar su capacidad para captar capital de riesgo para el mejor cumplimiento de sus proyectos de desarrollo y actuar en consecuencia».

«Definida esta capacidad de las cooperativas agropecuarias para emitir capital accionario, la reforma establece las siguientes bases y limitaciones»:

— «Las acciones podrán ofrecerse a asociados o terceros».

— «A este capital accionario no se le reconoce ningún derecho político».

— «El capital accionario será remunerado en la medida en que la cooperativa tenga excedentes repartibles y con los límites que establezca su asamblea».

— «La suma de sus sucesivas emisiones no podrá ser superior al patrimonio neto de la entidad». 
— «Los títulos deben ser nominativos, endosable o no».

— «Podrá hacerse oferta pública, sujetándose a la legislación vigente en la materia».

— «En caso de liquidación de la cooperativa las acciones serán reembolsadas con preferencia a las cuotas sociales representativas del capital accionario».

«Como el financiamiento es una importante restricción del desarrollo al cooperativismo agropecuario, la legislación prevee, además de la emisión del capital accionario, como se ha referido precedentemente, las alternativas de»:

— «Emisión de títulos de deuda cooperativa».

— «Reservas facultativas».

— «Establecimiento de un capital mínimo».

— «Capital proporcional».

— «Régimen especial para el reembolso de cuotas sociales» (7).

\section{COMENTARIO}

Este Proyecto de Ley será tratado en breve por la Cámara de Diputados de la Nación Argentina. Ya tiene aprobación de la Comisión de Agricultura y Ganadería y de la Comisión de Cooperativismo y Mutualismo.

El capital accionario, en tal caso debería estar expresamente contemplado en las previsiones Estatutarias, según las resoluciones de la Asamblea soberana de asociados. Dicho capital accionario ha de conformarse con arreglo a los antecedentes doctrinarios, a los dictámenes de la Alianza Cooperativa Internacional y a la experiencia jurisprudencial comparada.

Una eventual autorización legal de apertura en la captación del capital no debería generar derechos a participar en el gobierno de las entidades, puesto que dichas «acciones» tendrían un carácter de complemento, de ayuda, resfuerzo, pero nunca de reemplazo del postulado «self help» (esfuerzo propio y ayuda mutua), característico de la cooperación libre, que inspira al Movimiento cooperativo y ejercitan las cooperativas con el aporte de los asociados.

¿Existiría alguna contradicción doctrinal, en el hipotético caso que la legislación positiva de la República Argentina, permitiera captar capitales y remunerarlos, además de las previsiones de los Arts. 10 y 42 incs. 1, 2 y 3 de la Ley 20337? En principio, desde el punto de vista de 
la ética social, política y económica, si es «un precio justo», no ofrecería reparos. Por otra parte, desde la ciencia del Derecho y de la técnica-jurídica, ello es posible. Ahora bien, doctrinalmente hablando, según el Art. 4 de la Exposición de Motivos de la Ley N. ${ }^{\circ}$ 20337, el concepto de "acto de comercio» es sustancialmente distinto del «acto cooperativo», el cual «no implica operación de mercado sino la realización de un servicio social». Las cooperativas no pueden transformarse en «sociedades comerciales» o "asociaciones civiles», aunque pueden asociarse con personas de otro carácter jurídico, a condición de que no desnaturalicen su propósito de servicio social.

El Capítulo IV de la mencionada Ley General de Cooperativas, trata del Capital y las cuotas sociales y en el Art. 36 «explicita con mayor precisión el alcance del principio de irrepartibilidad de las reservas». El interés que eventualmente se pague sobre el capital accionario tiene una tasa limitada. Como todo capital, patrimonio, caudal, dinero, fortuna o bienes económicos, han de cumplir una función social, en vista de la generación de otros bienes o servicios. Este criterio es válido también para los negocios mercantiles y quienes disponen de rentas más que suficientes, que en lugar del disfrute egoísta, asumen el riesgo empresario y la responsabilidad consecuente, persiguiendo ganancias, pues no son, instituciones de beneficiencia. Por tanto es lógico suponer y aceptar una «justa retribución al capital».

La hora presente exige recibir el resultado de la experiencia, prudencia, sabiduría y ciencia de los teóricos y realizadores del «solidarismo social», rescatando lo más valioso de las experiencias socialcristiana, socialdemócrata y liberal.

Necesitamos decisión e inteligencia para demostrar la capacidad para el cambio de las cooperativas, como empresas cogestoras de la economía social en un ámbito de libertades Constitucionales. Como educadoras en el ejercicio de emancipación e independencia, con eficiencia y eficacia, las cooperativas han de captar capitales, para perfeccionar el gerenciamiento de recursos, para producir bienes y servicios gravosos, costosos, onerosos, propios del dinamismo o la actividad económica, para la calidad de vida de sus asociados y de la Sociedad civil.

La actividad económica es tarea o diligencia propia de la libre iniciativa privada (individual o asociada) y subsidiariamente del Estado. Si esto es así, la captación de capital, accesorio, auxiliar, secundario, en las cooperativas agrarias, contribuiría a la consolidación, crecimiento y expansión de las propias cooperativas, permitiéndoles la incorporación 
de tecnología de avanzada y la experiencia de las grandes organizaciones. A la difusión del capital; a la promoción de las inversiones productivas de las empresas pequeñas y medianas, entre otras las agrícolo-ganaderas e industriales. A defender las fuentes de trabajo y la dignidad humana de los cooperativistas y usuarios. A mostrar el rol social de la economía, y superar la especulación por la productividad. A competir en el ámbito de las integraciones regionales y participar en las oportunidades que ofrecen los grandes espacios geopolíticos, geoestratégicos y geoeconómicos. A acrecentar la cooperación entre el capital y el mundo del trabajo. A transformar el capital en instrumento de productividad y acrecentamiento de la justicia, la libertad, la igualdad y la fraternidad, para perfeccionar la democracia política, económica y social. A posibilitar el cumplimiento de las obligaciones sociales de quienes más poseen bienes materiales. A la armonía y a la paz social. A «estimular y dignificar el trabajo». A «impulsar el desarrollo económico con justicia social». A que el Estado cumpla con los Principios de bien común, solidaridad y subsidiariedad tal como han sido definidos por la Doctrina Social Cristiana. A «proteger la institución familiar, a estimular el ahorro popular y las inversiones productivas». A consolidar una sociedad civil de libertades y solidaridades operantes en un todo acorde con el ideario democrático, participativo, el humanismo y la ética pública; en suma, a constituir un Estado de Derecho y de Justicia Social como es auspiciado por la Constitución de la Nación Argentina (1994) Arts.: 36, 37, 38, 39, 40, 41 y Art. 75 inc. 19 y 22.

En el Capítulo Il de la Ley N. 19550 (sobre "Sociedades Comerciales»), se encuentran criterios que clarifican las cuestiones accionarias de las sociedades comerciales y que podrían contribuir supletoriamente a enriquecer el debate, en tanto no colisionen con la Ley N. 20337 en cuanto a «la naturaleza de las cooperativas». No se trata de forzar una interpretación heterodoxa de la Doctrina Cooperativa, sino de preguntarnos por el modo más idóneo y eficaz de optimizar el gerenciamiento de los recursos escasos.

\section{NOCIONES (8)}

VI.1. La Entidad Cooperativa participa del concepto amplio de toda "asociación», porque posee la característica común de asociarse libremente, en forma organizada, para el logro de fines específicos, en procura del bien colectivo de los asociados. 
VI.2. Basándose en el rédito económico, el derecho societario establece una distinción entre «sociedades» y «asociaciones». El rédito (beneficio, ganancia, utilidad, provecho o lucro) constituiría un recurso, del cual toda "asociación» se serviría, como medio, para realizar los fines y objetivos propuestos. En cambio, para las "sociedades», ese rédito consistiría, como fin, en un lucro repartible entre los socios.

VI.3. La diferencia fundamental: la «sociedad» propone algo entre los socios, mientras que la «asociación» propone algo por encima de los socios.

Por tanto: El «asociacionismo cooperativo» se distingue de las «sociedades», participando del concepto de «asociaciones».

VI.4. Nuestra postura no es adversa a la finalidad de las «sociedades comerciales», porque la actividad económica ha de ser responsabilidad prioritaria, pero no exclusiva, de la libre iniciativa, aunque sin impedir la acción subsidiaria del Estado para promover el bien común y afianzar la justicia social.

VI.5. La economía debe estar subordinada a la ética social, porque acorde con el Magisterio de la Doctrina Social Cristiana «la Persona Humana es sujeto, fundamento y fin de la sociedad y de sus estructuras».

VI.6. El Movimiento Cooperativo surgió en 1844, en Inglaterra como reacción moral frente a los abusos del materialismo capitalista ortodoxo, aunque esta doctrina clásica ha evolucionado aceptando las ventajas de la práctica cooperativa.

VI.7. En Argentina, el derecho de comerciar tiene garantía Constitucional, como así también la libertad de asociarse con fines útiles. Por ende, la organización cooperativa encuentra sustento jurídico en dichas garantías.

VI.8. Las Cooperativas constituyen la expresión práctica de la garantía constitucional atinente a la «libertad de asociación con fines útiles».

VI.9. La actividad cooperativa contribuye al logro del «bienestar general» que anima la acción subsidiaria del Estado en función socioeconómica del bien común.

VI.10. La Constitución Provincial de Santa Fe proclama y reafirma, en su Preámbulo, los principios de cooperación y solidaridad sociales: 
reconoce, fomenta, promueve y fiscaliza la acción cooperativa en los Arts. 26 y 28.

VI.11. El sistema cooperativo, por la concepción universalista de su filosofía social y económica, reclama su regulación legal por parte del Estado, para impulsar su promoción, fomento y fiscalización.

VI.12. El Derecho ha de integrar el fenómeno socioeconómico en evolución, incorporándolo a las normas del ordenamiento jurídico de la sociedad.

Por tanto: El derecho positivo, siendo el medio eficaz del cual se sirve el Estado para cumplir su misión esencial, no podría desconocer la trascendencia cultural del cooperativismo en la transformación de la economía social del País.

VI.13. Con el aporte eficaz del trabajo, cada individuo coopera con sus semejantes, contribuyendo a la realización colectiva de los fines comunitarios para el logro del bien común.

VI.14. El trabajo individual se convierte en un deber social, puesto que la sociedad actúa como medio de realización de la existencia humana. Por ende, toda actividad, en función de convivencia, es subsidiaria y prestacional.

VI.15. «Subsidiariedad» y "Cooperación» constituyen principios reguladores del solidarismo social: sirven de "principio-medio» para un «principio-fin», cual es el bien propio en procura del bien común.

VI.16. La cooperación social implica la integración de los grupos humanos en acción solidaria para la consecución del objeto y fin societario (bien común de los asociados).

VI.17. El ideario cooperativo se inspira en el espíritu de integración comunitaria, democrática, libre, pluralista y participativa.

VI.18. Por ende, el cooperativismo participa del solidarismo social, porque se funda en el esfuerzo propio y cooperante de cada miembro, apoyándose en la solidaridad que proviene de la ayuda recíproca de todo el grupo que lo integra.

VI.19. Por tanto: La institución cooperativa —en su tipificación socio-jurídica - se distingue de los demás sujetos del Derecho Comercial («sociedades comerciales»). 
VI.20. La naturaleza jurídica propia del asociacionismo cooperativo lo distingue de otras ramas del Derecho, justificándose su especialización científico-jurídica.

En julio de 1986 se realizó en la ciudad de Rosario, R.A., el «Ill Congreso Continental de Derecho Cooperativo», convocado por la Organización de Cooperativas de América, con el auspicio de las Universidades: Católica Argentina y Nacional de Rosario; del Colegio de Abogados y la Secretaría de Acción Cooperativa, concurriendo entre otras personalidades el entonces Primer Mandatario de la Nación Argentina. En dicha oportunidad he sostenido que del concepto de "acto cooperativo» depende la determinación del objeto y contenido del Derecho Cooperativo, proporcionando a éste su propia sustantividad jurídica. Por tanto, evidencia poseer condiciones predisponentes o presupuestos para una autonomía científica. El acto cooperativo se inscribe en la doctrina sociojurídica y socioeconómica de la cooperación libre y demanda un Derecho con fisonomía propia acorde a estas organizaciones económicas de servicio social. El nuevo Derecho propiciado posee sustancia y forma de características singulares, en condiciones más que suficientes para evolucionar hacia un sistema homogéneo de normas orgánicas, instituidas con autonomía al menos sistemática y didáctica (9).

\section{PRESENTE Y FUTURO}

Ante el vilipendio de los Derechos Humanos fundamentales, reclamamos que el Constitucionalismo garantice las libertades, derechos y obligaciones esenciales, que integran el bien común evolutivo y dinámico. Es deber del Estado y de los mandatarios del pueblo promover y asegurar la efectiva vigencia de los preceptos rectores del orden social: justicia, solidaridad, subsidiariedad, para el «desarrollo integral» y la paz que propugna la ONU. Los intelectuales, por su parte, han de esforzarse en lograr una "Teoría integral del Desarrollo». Frente al auge avasallante de la «globalización» financiera e intercomunicacional, conviene insistir en los efectos de la libertad que expresa la eminente dignidad de la persona humana, pues la vida económica mundial necesita una ética de la solidaridad que la perfeccione.

En mi concepto el gran desafío actual es educar en una cultura de la calidad de vida para el ejercicio responsable de nuestras libertades y por ende la cuestión es de carácter filosófico e involucra la ética social, politi- 
ca y económica. La Real Academia Sueca, con motivo de anunciar el Premio Nobel de Economía 1998, destacaba que Amartya K. Sen, PhD., defensor de la tesis del udesarrollo como libertad (...) al combinar las herramientas económicas con las filosóficas ha restaurado la dimensión ética del debate sobre los problemas económicos más vitales...» (10).

Para la sociedad y en la cultura del futuro próximo es vital fomentar el estudio de las ciencias, por ello insisto en la importancia que reviste el intercambio de conocimientos científicos, como en esta oportunidad en que intento una «aproximación al tratamiento del capital en las cooperativas». Ello coadyuva a la evolución legal y enriquece las «distintas disciplinas que confluyen en la economía social». De ahí mi vivo aprecio por la «International Association of Cooperative Law»y por un Cooperativismo sustentable, es decir creible, deseable y posible. Este puede ser estudiado desde la multidisciplinariedad y realizado sistemáticamente, mediante el «esfuerzo propio y la ayuda mutua», como lo postula la «Cooperación Libre».

\section{CITAS BIBLIOGRAFICAS, NOTAS DE REFERENCIA Y DE CONTENIDO}

(1) Muraro, Jorge Sebastián, en «El Solidarismo», Diario La Opinión, Rafaela, Sta. Fe, R.A., 07/06/00, pág. 6.

(2) Frías, Pedro José, «Reportaje del Sr. Emilio Oscar Grande», Diario La Opinión, Sta. Fe, R.A., 20/01/97, pág. 13.

(3) Grondona, Mariano, Hacia una Teoría del desarrollo. Las condiciones culturales del desarrollo económico, Ariel-Planeta, Bs.As., 1999.

(4) Constitución de la Provincia de Santa Fe (1962), Zeus Editora, Rosario, Sta. Fe, R.A., 1982. Constitución de la Nación Argentina (1994), Edic. del Colegio de Abogados de Sta. Fe, R.A., 1994. Constitución de la Provincia de Bs.As., R.A., (1994), Ediciones Ciudad Argentina, Bs.As., R.A., 1999, Impreso en Madrid, España por I.Fareso S.A., 1999. Constitución de la Ciudad Autónoma de Bs.As. (1996) Edic. Ciudad Argentina, Bs.As., R.A., 1999, Impreso en Madrid, España por I.Fareso S.A., 1999.

(5) Alvarez Vélez, M. ${ }^{a}$ Isabel, Alcón Yustas, M. ${ }^{a}$ Fuencisla, Las Constituciones de los Quince Estados de la Unión Europea (Textos y Comentarios), Dykinson, Madrid, España, 1996:

a) «Régimen Constitucional de Alemania», págs. 11 a 21. "Constitución de la RFA», págs. 23 a 64.

b) «Régimen Constitucional de Francia», págs. 299 a 305. "Constitución de la República Francesa», págs. 307 a 322.

c) «Régimen Constitucional de Italia», págs. 407 a 413. «Constitución de la República Italiana», págs. 415 a 438. 
d) «Régimen Constitucional de España», págs. 205 a 212. "Constitución Española», págs. 213 a 247.

(6) Ley N. 20337/73, INAC, Boletín Público, Año 1, T. ${ }^{\circ}$ I, Bs.As., R.A., Junio de 1973, Cap. IV, Arts. 24 a 36.

(7) Proyecto de Ley de Cooperativas Agrarias, de los Señores Diputados de la Nación Argentina: Volando, Humberto (Vicepresidente $2 .^{\circ}$ de la Comisión de Agricultura y Ganadería), Salvatori, Pedro; Balestra, René; DuMON, José; DraGICEVIC, Carmen; Bs.As., 2000. Expediente 4956-D-99.

(8) La bibliografía de este apartado se encuentra en:

- LunA, Ernesto G.F., Naturaleza Socio-Jurídica de las Cooperativas, Universidad Notarial Argentina, La Plata, Pcia. de Bs.As., R.A., 1995.

- Cfr.: Ley N. ${ }^{\circ}$ 20337/73, Instituto Nacional de Acción Cooperativa (I.N.A.C.), Boletín Público Año 1, T. I, Bs.As., R.A., Junio de 1973.

— Ley N. 19550 de "Sociedades Comerciales», con las Modificaciones de la Ley 22903. Texto Ordenado por Decreto N. ${ }^{\circ} 841$ del 20/03/84 del Poder Ejecutivo Nacional, Editorial Bregna, Bs. As., R. A., 1984.

— «Cooperar»: Enciclopedia Universal Ilustrada Europeo Americana, Espasa-Calpe S.A., Madrid y Barcelona, España, T. 15, pág. 340-341.

— «Cooperación»: DrIMER, Bernardo y KAPLAN, Alicia de, Las Cooperativas, Intercoop. Editora Coop. Ltda. Y FACC, Federación de Cooperativas de Consumo Ltda., 1975, págs. 15 y 16.

— «Cooperativismo»: BALAY, Esteban, Bases del Ordenamiento Cooperativo de la Economía Social, Artes Gráficas Bartolomé U. Chiesino, S.A., 1975, págs. 568 a 570.

— Farina, Juan, Sociedades Comerciales, Zeus Editora, Rosario, 1972.

- «Carta de Mérida», Venezuela 1969, Primer Congreso Continental de Derecho Cooperativo.

- Althaus, Alfredo A., Tratado de Derecho Cooperativo, Zeus Editora, Rosario, 1974, pág. 5 passim.

— «Beneficio»: Enciclopedia Jurídica Omeba, T. II, Editorial Bibliográfica Argentina, 1955, pág. 123.

- Ensayo de un Diccionario Español de sinónimos y antónimos, 4 Edición, de Federico C. Sainz de Robles, Madrid, Edic. Aguilar, 1955, pág. 159.

- LuNA, Ernesto G.F., Significación Sociocultural del Cooperativismo, UNL, Universidad Nacional del Litoral, Sta.Fe, R.A., 1979.

- Luna, Ernesto G.F., Naturaleza y Funciones de la Autoridad Política, U.del S., Universidad del Salvador, Bs.As., R.A., 1989.

- LunA, Ernesto G.F., La Política Exterior Argentina. Transnacionalización e Interdependencia, U. del S., Universidad del Salvador, Bs.As., R.A., 1994.

- Véase: Cuesta, Elsa, Manual de Derecho Cooperativo, Ed. Abaco de Rodolfo Depalma, Bs.As., R.A., 2000.

— «Rédito»: Código Civil Argentino, Tit. VII. «De la Sociedad». Cap. 1. "Condiciones esenciales para la existencia de la sociedad», Bs.As., Víctor Zavalía Editor, Bs.As. 1970, pág. 370. 
- Ley 20337/73, INAC, Boletín Público, Año 1, T. ${ }^{\circ}$ I, Junio de 1973, Art. 1. y $2 .^{\circ}$ inc. 1 al 12, Cap. I «Naturaleza y Caracteres».

— «Bien Común»: Concilio Vaticano II, Constitución Pastoral Gaudium et Spes, N. ${ }^{\circ} 74$, JuAn XXIII, Encíclica Pacem in Terris, N.os 53 y 54, Encíclica Mater et Magistra, N. ${ }^{\circ} 14$.

— «Sistema Social del trabajo...»: Pesch, Heinrich, Lehrbuch der Nationalökonomie, (1924), Tratado de Economía Nacional.

- Gely, R.A., Zur Soziologie des Solidarismus (1973), Sociología del Solidarismo.

- Muraro, Jorge Sebastián, Sociedad, Estado, Bien Común, Rosario, Edic. La Capital, 1979, pág. 6.

- Muraro, Jorge Sebastián, Los Fenómenos del Poder, Rosario, Edic. La Capital, 1979. 6.

- Muraro, Jorge Sebastián, Fin y Bien del Hombre en Sociedad, Rosario, Ediciones La Capital, 1980, págs. 4-6.

- Muraro, Jorge Sebastián, Principios éticos del Orden Social, Ediciones La Opinión, Rafaela, Sta. Fe, R.A., 1998, p.6.

- Muraro, Jorge Sebastián, La Justicia en los repartos Sociales, Ediciones La Opinión, Rafaela, Sta. Fe, R.A., 1998, p.6.

- Muraro, Jorge Sebastián, Principio Jerárquico ordenador de la función Social, Edic. La Opinión, Rafaela, Sta. Fe, R.A., 1995, pág. 6.

- SÁnchez Agesta, Luis, "El Principio de la función subsidiaria», en Revista de Estudios Políticos N. ${ }^{\circ}$ 121, pág. 21, passim, Madrid, Inst. Estudios Políticos 1962.

— Ley N. ${ }^{\circ}$ 11388/26, Anales de Legislación Argentina, T. ${ }^{\circ}$ XXII-B. Editorial La Ley, Bs.As., 1972.

— LuNA, Ernesto G.F., «Significación del Proceso de Integración Regional», en Revista de la Escuela Superior de Gendarmería Nacional, Año 8, N. ${ }^{\circ} 15$, Bs.As., R.A., Julio de 1994, págs. 43 y s.s.

— LunA, Ernesto G.F., «Derecho Cooperativo: Socio-economía libre», Diario La Opinión, Rafaela, Pcia. Sta.Fe, R.A., 15/02/01, pág. 6.

(9) Cfr. LunA, Ernesto G.F., «Autonomía del Derecho Cooperativo», en Anales del III Congreso Continental de Derecho Cooperativo, Idelcoop-Intercoop. Bs.As., R.A., 1987, págs. 82 a 91.

(10) Sen, Amartya K, PhD., (Premio Nobel de Economía), Desarrollo y Libertad, Planeta, Bs.As., R.A., 2000.

\section{NOTICIA DEL EXPOSITOR}

Ernesto Gaspar Francisco LUNA, miembro correspondiente en Santa Fe de la Academia Argentina de Asuntos Internacionales, nació en San Javier, Pcia. de Sta. Fe, en 1947. Posee los títulos de: «Doctor en Relaciones Internacionales» (U. del S.), «Magister en Estupefacientes» 
(U.C.S.), «Doctor en Ciencia Política» (U. del S.), «Doctor en Notariado» (U.N.A.), «Doctor en Ciencias Jurídicas y Sociales» (U.N.L.), «Abogado» (U.C.S.F.), «Licenciado en Cooperativas» (U.C.S.F.) y actualmente, «Maestrando en Administración Pública» (U.N.L).

Teniendo en cuenta sus antecedentes, adhesión a los Derechos Humanos y su compromiso con el ideario Republicano, el estilo de vida democrático, el pluralismo ideológico y el ecumenismo religioso, el Gobierno Constitucional le concomendó (1986-1994) la participación académica en los temas inherentes a Defensa Nacional y Seguridad Pública. Ha egresado entre otros post-grados: del XXXIV Ciclo de Estudios Superiores de la Escuela de Defensa Nacional; del PostGrado de "Administración-Dirección Estratégica y Alta Dirección» de la Escuela Superior de Guerra del Ejército Argentino, del Curso de «Teoría de la Decisión» de la Escuela Superior de Gendarmería Nacional, del Curso de «Estrategia» del Estado Mayor Conjunto de las Fuerzas Armadas Argentinas, en la Escuela de Guerra Naval. Profesor Titular de «Política Internacional Contemporánea», "Sociología General», "Seminarios IV y V - Política», "Movimientos Sociales y Políticos del Siglo xx», "Sistema Político Argentino» y «Análisis Político-Social Mundial», en la Facultad de Ingeniería y Tecnología Informática de la Universidad de Belgrano, Bs.As., donde ha sido Profesor de otras asignaturas y Consejero Académico. Asimismo es Profesor Titular en la Facultad de Ciencias de la Salud de la UB, en la Cátedra de «Política Internacional Contemporánea». Miembro de la Asociación Internacional de Derecho Cooperativo, Universidad de Deusto - Bilbao - España y de la Sociedad Científica Argentina. Ex Catedrático de la UNL, UCSF y UCS., ex Asesor de Asuntos Universitarios y ex Director Académico —ad honorem - de la Carrera de Grado de «Licenciatura en Relaciones Internacionales», en la sede Gendarmería Nacional, Buenos Aires de la Universidad Católica de Salta.

En el año 1970, ingresó como funcionario de la planta de personal permanente de la Administración Pública y se desempeña como Sub Director General de Despacho y Servicio Interministerial del Ministerio de Hacienda y Finanzas de la Pcia. de Santa Fe, por derecho de concurso, habiendo ejercido cargos en la Administración Nacional, Provincial y Municipal. Comparte su actividad personal en instituciones sociales, científicas, culturales, políticas y de bien común. Numerosas han sido sus conferencias en temas de su especialidad, participando en programas organizados por distintos medios de comunicación 
social e interviniendo en Congresos, Cursos, Simposios y Seminarios de Investigación con exposiciones interdisciplinarias, contribuyendo al análisis doctrinario en aspectos de la problemática nacional e internacional con sus colaboraciones periodísticas y de sus trabajos en revistas especializadas. 